\title{
A VIDA COTIDIANA E AS BRINCADEIRAS NO PRIMEIRO ANO DO ENSINO FUNDAMENTAL
}

\author{
Maria Silvia Pinto de Moura Librandi da Rocha ${ }^{1}$ \\ Rosângela Benedita Ribeiro ${ }^{2}$
}

\begin{abstract}
RESUMO: Discute-se se e de que forma a atividade lúdica tem integrado o currículo de primeiros anos do ensino fundamental. Para tal, apresentam-se resultados de pesquisa bibliográfica, realizada na Biblioteca Digital Brasileira de Teses e Dissertaçóes (BDTD), articulados a resultados de pesquisa empírica, realizada em uma turma de primeiro ano de uma escola municipal. A partir desses, problematizam-se: (i) escassa inserção de brincadeiras no cotidiano escolar; (ii) identificação de algumas brechas em que elas ocorrem; (iii) predomínio de jogos de exercício e de regras; e (iv) baixa frequência, curta duraçáo e simplicidade das brincadeiras de faz de conta.
\end{abstract}

Palavras-chave: Ensino fundamental de nove anos. Atividade lúdica. Teoria histórico-cultural.

\section{Daily life and playful activities in the first year of elementary school}

\begin{abstract}
The discussion is about if and how playful activities have been added to the syllabus of the initial years of the elementary school. To support it, the results of the bibliographic research, conducted in the Brazilian Digital Library of Theses and Essays (Biblioteca Digital Brasileira de Teses e Dissertaçóes - BDTD),
\end{abstract}

\footnotetext{
${ }^{1}$ Pontifícia Universidade Católica de Campinas, Programa de Pós-graduação em Educação Campinas (SP), Brasil. E-mail: silrocha@uol.com.br

${ }^{2}$ Centro Universitário de Itajubá - Itajubá (MG), Brasil. E-mail: roribeirodm@gmail.com DOI: 10.1590/CC0101-32622017173572
} 
are presented in connection with the results of the empirical research conducted in a first-year classroom of a municipal school in Campinas, Sáo Paulo, Brazil. Based on such results, the following points are raised: (i) scarce games/playful activities in the school routine; (ii) identification of some gaps where such activities may take place; (iii) majority of exercise and rule-driven games; and (iv) low-frequency, short-duration and simple roleplay activities.

Keywords: Nine-year Elementary School. Playful activity. Historical-cultural theory.

\section{INTRODUÇÃO}

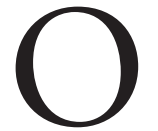

ano de 2006, data da publicação da Lei Federal no 11.274 , representa um importante marco para a educação brasileira, ao ampliar a duraçáo do ensino fundamental (EF) para nove anos e instituir a obrigatoriedade do ingresso das crianças nas escolas aos seis anos de idade. É certo, porém, que esses elementos são apenas a face mais visível das mudanças pretendidas com o novo sistema de escolarização.

Os documentos do Ministério da Educação do Brasil que estabelecem as diretrizes pedagógicas do EF preconizam que a reorganização curricular leve em conta dois elementos essenciais:

1. que o cotidiano do primeiro ano respeite características peculiares das crianças de seis anos;

2. a importância de que, na esteira da ampliação da duração do EF, articule-se ampliação de oportunidades de aprendizagem e de experiências para todos os alunos de todos os anos, vinculadas a novas formas de organizar o tempo, o espaço e as práticas pedagógicas (BRASIL, 2004, 2006, 2009).

Dentre várias indicaçôes sobre quais aprendizagens e experiências devem ser garantidas as que se referem à atividade lúdica são bastante ressaltadas, como nos trechos a seguir: 
[...] o brincar como um modo de ser e estar no mundo; o brincar como uma das prioridades de estudo nos espaços de debates pedagógicos, nos programas de formação continuada, nos tempos de planejamento; o brincar como uma expressão legítima e única da infância; o lúdico como um dos princípios para a prática pedagógica; a brincadeira nos tempos e espaços da escola e das salas de aula; a brincadeira como possibilidade para conhecer mais as crianças e as infâncias que constituem os anos/séries iniciais do ensino fundamental de nove anos (BRASIL, 2006, p. 11-12).

Com base em pesquisas e experiências práticas, construiu-se uma representação envolvendo algumas das características das crianças de seis anos que as distinguem de outras faixas etárias, sobretudo pela imaginação, a curiosidade, o movimento e o desejo de aprender aliados à sua forma privilegiada de conhecer o mundo por meio do brincar (BRASIL, 2004, p. 19).

Assumindo como fundamento a teoria histórico-cultural, esclarecemos que não partimos do princípio da existência de características essenciais das crianças. Nesse modelo teórico, entende-se que as características de cada sujeito e possíveis regularidades psicológicas entre sujeitos de um mesmo período etário decorrem de regularidades das condiçóes e atividades educacionais (em sentido amplo) da cultura a que pertencem. Não são genéricas. Logo, um dos traços mais indicados a respeito das crianças de seis anos - sua capacidade imaginativa — não é inato e/ou incondicional, mas resultante do fato de que, na nossa cultura, as crianças, em geral, participam de um conjunto de atividades em que a imaginação pode constituir-se e desenvolver-se, como a literatura infantil, desenhos, pinturas e brincadeiras de faz de conta. Feita essa ressalva, o que se ressalta nos documentos é consonante com o que na teoria histórico-cultural é considerada atividade principal para o desenvolvimento das crianças pré-escolares: a atividade lúdica ${ }^{1}$.

Dessas considerações originaram-se as questóes discutidas neste artigo: como, efetivamente, vem se configurando a vida cotidiana e as práticas pedagógicas do EF? Nessa configuração, que lugar é destinado 
às brincadeiras? Buscamos responder essas perguntas primeiramente a partir de resultados de ampla revisão bibliográfica; em seguida, aprofundamos um ponto específico desses resultados: os momentos do cotidiano em que se indica a ocorrência de brincadeiras; esse aprofundamento será feito por meio de estudo empírico, acompanhando uma turma de primeiro ano de escola pública.

\section{PANORAMA NACIONAL DO ENSINO FUNDAMENTAL DE NOVE ANOS: A LINGUAGEM ESCRITA E A ATIVIDADE LÚDICA EM FOCO}

A pesquisa bibliográfica foi desenvolvida na Biblioteca Digital Brasileira de Teses e Dissertaçóes (BDTD), buscando trabalhos publicados de 2008 a 2015, com os termos "ensino fundamental de nove anos" e "ensino fundamental de 9 anos". A leitura de títulos e resumos de 1.432 pesquisas permitiu selecionar as que focalizavam o primeiro ano do EF (91). Nessas, mostra-se que os desafios para construir um novo currículo têm sido múltiplos, complexos e de origens diversas.

Considerando os estudos em seu conjunto, foram ouvidos representantes dos principais envolvidos: por várias composiçóes de procedimentos (prevalecendo entrevistas e observação), estão presentes professores, alunos, pais, orientadores pedagógicos, secretários de educação; no caso das observaçóes, o dia a dia das crianças de seis anos de idade foi acompanhado nas salas de aula, nas aulas de Educação Física, no recreio, pátios, parques, quadras esportivas e em brinquedotecas. Com forte regularidade, os pesquisadores tematizaram duas esferas de atividades: a atividade lúdica (70 trabalhos) e as relacionadas ao campo da linguagem escrita (51), muitas vezes fazendo consideraçóes sobre ambas (40). Em relaçáo a essas esferas, os estudos mostram que a implementação do EF seguiu tendências opostas, detalhadas a seguir.

As pesquisas que focalizaram práticas relativas à linguagem escrita mostram que elas foram o ponto central do trabalho de professores de primeiros anos. Dentro desse campo, examinaram-se atividades de letramento e alfabetização, em várias formas: jogos para alfabetização, produção de textos, cópia, leitura, caligrafia, contação de histórias, ditados, uso de 
apostilas, idas à biblioteca, atividades em artes e música, dentre outras. Embora no conjunto geral sejam descritos trabalhos bastante diversificados, em muitos contextos escolares prevaleceram atividades mecânicas de alfabetização: via de regra, as crianças dos primeiros anos passaram muitas horas sentadas nas carteiras, envolvidas em cópias descontextualizadas e pouco inovadoras, com lápis, caderno, lousa e giz (MARCONDES, 2012; CHULEK, 2012; OLIVEIRA, 2011). Evidencia-se, assim, pouco impacto do que se prescrevia como meta a ser atingida:

[...] não se trata de realizar um "arranjo" dos conteúdos da primeira série do ensino fundamental de oito anos. Faz-se necessário elaborar uma nova proposta político-pedagógica e curricular [...] (BRASIL, 2009, p. 24).

Quanto à atividade lúdica, sua inclusão no cotidiano é inversamente proporcional às de alfabetização. As pesquisas registraram que nos primeiros anos a ocorrência de brincadeiras tem sido incipiente. É certo que existem variaçóes, pois em poucas escolas instalaram-se equipamentos de parque (do tipo gangorra, balanço, casinhas de madeira), brinquedotecas e foram adquiridos brinquedos e jogos de regras (esses últimos mais frequentes e do tipo pedagógico) e algumas professoras confeccionaram jogos pedagógicos. A estratégia do "dia do brinquedo" também foi inserida em algumas turmas. Entretanto, mesmo nessas situaçóes, frequentemente a possibilidade de brincar foi ofertada às crianças como recompensa pelo trabalho realizado, recurso para que fizessem a lição e/ou sua privação como punição por mau comportamento ou baixa adesão às tarefas (OLIVEIRA, 2013).

Tendo em perspectiva essa conjuntura de escassas oportunidades de brincadeiras, fortemente vinculadas a iniciativas individuais de professoras, a revisão bibliográfica indica três circunstâncias do cotidiano em que as crianças brincaram: no recreio, nas aulas de educaçáo física e nos interstícios das atividades nas salas de aula (SANTOS, 2013; MARCONDES, 2012; MARTINATI, 2012; NOGUEIRA, 2011; SILVA, 2011). Esses resultados também foram encontrados em nossos trabalhos, realizados em primeiros anos, desde 2006 (ROCHA, 2009). A partir de pesquisa feita em 2011, aprofundamos as análises em relação 
a esse tópico, buscando responder à seguinte pergunta: de que as crianças brincam nesses contextos?

\section{NA SALA, NO RECREIO, NA EDUCAÇÃO FÍSICA: DIFERENTES CONTEXTOS, DIFERENTES BRINCADEIRAS}

Antes de abordarmos o material empírico, é necessário demarcar, conceitualmente, a que nos referimos quando tratamos da atividade lúdica. Primeiramente, examinamos o uso disseminado da palavra lúdico e derivaçóes; em seguida, apresentamos definiçóes das modalidades de brincadeiras nas quais baseamos nossas análises.

Os termos "lúdico" e "lúdica" têm sido utilizados de distintas formas e em múltiplas composiçóes: "o lúdico”, "vivência lúdica”, "encantamento lúdico", "atmosfera lúdica”, "cultura lúdica”, "atividade lúdica”, "ludicidade”. O significado dessa última expressão é bastante amplo:

"Ludicidade" [...] significa o processo dinâmico e a propriedade comum às situaçôes onde "o lúdico" está presente. [...] Portanto, o termo "lúdico" é muito mais do que uma atividade em si, mas uma experiência significativa que se dá através da articulaçáo de diversos conteúdos culturais. [...] O "lúdico" é também um "clima" e uma atitude dos sujeitos envolvidos, que podem estar presentes na aula de matemática ou leitura, embora mais facilmente percebido nos jogos e brincadeiras, na medida em que a ludicidade é característica marcante da cultura infantil (AZEVEDO, 2012, p. 198).

Em síntese, tudo o que se faz e que gere prazer, satisfação, alegria parece adequar-se a essas expressóes, usadas como sinônimos de "ambiente escolar interessante e leve", "postura descontraída", "espontaneidade", "aleatoriedade" etc.; nelas incluem-se diferentes atividades, desde as mais tipicamente associadas à infância (brincadeiras, cantigas, atividades plásticas) até as relacionadas a campos de conhecimento escolar, como se propóe na definição acima. 
$\mathrm{Na}$ teoria histórico-cultural, entretanto, essa questão é tratada de forma diferente. Ao definir o que são as brincadeiras, Vigotski alerta para a impropriedade de associaçóes entre elas e o sentimento de satisfação. A seguir, alguns de seus argumentos:

Sabemos que a definição de brincadeira, levando-se em conta como critério a satisfação que ela propicia à criança, náo é correta por dois motivos. Primeiramente, porque há uma série de atividades que podem proporcionar à criança vivências de satisfaçáo bem mais intensas do que a brincadeira.

$[\ldots]$

Por outro lado, conhecemos brincadeiras em que o próprio processo de atividade também não proporciona satisfação. São aquelas que prevalecem no final da idade pré-escolar e no início da idade escolar e que trazem satisfaçáo somente quando seu resultado revelase interessante para a criança; é o caso, por exemplo, dos jogos esportivos [...]. Muito frequentemente, eles são tingidos de um sentimento agudo de insatisfação quando o seu término é desfavorável para a criança.

Dessa forma, a definição da brincadeira pelo princípio de satisfação, é claro, não pode ser considerada correta (VIGOTSKI, 2008, p. 23).

Aos argumentos de Vigotski acrescentamos que também as brincadeiras de faz de conta costumam ser permeadas por disputas, conflitos, tensôes, insatisfaçôes... Isso não quer dizer que deixaram de ser lúdicas. A seguir, dois excertos envolvendo crianças de quatro a cinco anos, de uma turma de educação infantil (EI), nos ajudam a refletir sobre a questáo em pauta.

As crianças há vários dias, brincam no parque, de temáticas diversificadas e simultâneas: creche, lojas, casinhas, posto de saúde e um salão de cabelereiro. Há também um "ônibus" (feito com uma caixa grande de papelão e uma alça para pendurar no ombro do "motorista") e um "guichê" (que funciona sempre em uma estrutura de alumínio, destinada a pendurar vasos) em que "vendem-se passagens". 


\section{No guichê}

Carla está vendendo passagens de ônibus. Bruna e Rafaela aproximam-se ${ }^{2}$.

1. Bruna: Ô moça, dá uma passagem.

2. Carla: Tem que esperar o ônibus [Carla não quer vender passagem para Bruna].

3. Bruna: Mas já tá escurecendo, eu preciso ir no posto, levar minha filha [com discreto gesto aponta Rafaela]. do guichê].

4. Carla: Não! Vai fechar [gesto de quem fecha a janela

5. Bruna: A moça fechou a porta! [dirige-se à professora]

6. Carla: Fechado para o almoço!

7. Bruna pega Rafaela pela mão e diz, visivelmente aborrecida:

8. Bruna: Entấo vamos a pé no posto.

\section{No saláo de beleza}

9. Júlia: Eu vou cortar o cabelo dela e passar creme [refere-se à Kesy]. Quer cortar o cabelo Paulo?

10. Júlia: Tô passando a máo de creme no cabelo dela [pega uma folha de árvore, vira-a sobre a mão e chacoalha, como se estivesse vertendo "creme da embalagem"].

11. Professora: E o que mais pode ser feito num salâo? Vamos fazer unha?

12. Kesya: Eu quero pintar a unha.

13. Júlia: Eu vou pintar a unha dela, mas eu quero silêncio.

14. Bia: Por que, Julita?

15. Júlia: Porque meu dodói tá doendo.

16. Júlia "passa esmalte" na unha de Kesya, fazendo gesto com os dedos, sem nenhum objeto substitutivo como pincel do esmalte. 
esticada]

17. Júlia: Deixa a unha aí pra secar. [coloca a mão de Kesya

18. Júlia: Eu não gosto de teimosia aqui no salão, né Kesya?

19. Bia: Agora é o meu.

20. Júlia: Me dá o batom.

21. Bia: Espera aí.

22. Júlia: Ah, então eu vou mandar a Bia embora e ela nunca mais vai cortar o cabelo aqui no salão.

23. Bia: Eu tô pondo o batom e a maquiagem [faz gestos em seu próprio rosto].

24. Júlia: Coloca o creme no cabelo da menina que tá seco [passa a mão no cabelo da Kesya].

[Bia pega uma embalagem plástica.]

25. Júlia: Não é este o creme!!! [tira, bruscamente, a embalagem de Bia e aponta outra, muito semelhante].

26. Júlia: É este!!

27. Bia pega a outra embalagem, chacoalha "vertendo o creme” na mão e passa no cabelo de Kesya.

Nestes dois episódios há interações marcadas por sofisticadas capacidades imaginativas das crianças, exploradas mais à frente, para contrastarmos com as brincadeiras envolvendo crianças do EF. Cabe aqui destacar que as relações entre os participantes não são o tempo todo harmônicas e/ou alegres. No desenrolar das cenas, Carla e Júlia controlam o enredo, impondo restriçóes às açóes de suas colegas e gerando visíveis desconcertos, aborrecimentos e submissóes.

Considerando-se, portanto, que o conceito de brincadeira assumido não se pauta pela presença obrigatória de prazer/satisfação das crianças, é necessário avançar um pouco mais e trabalhar com a definição de três de suas modalidades: jogos de exercício, faz de conta e jogos de regras. 


\section{A ATIVIDADE LÚDICA: MODALIDADES, ORIGEM E DESENVOLVIMENTO ${ }^{3}$}

Os jogos de exercício surgem com ações sensorimotoras, como chacoalhar um objeto sonoro e desenvolvem-se em atos como escorregar, balançar, correr etc. Caracterizam-se pelo prazer na repetição de movimentos e em seus resultados imediatos.

Já nos jogos de faz de conta, as crianças realizam ações simbólicas, utilizam objetos como se fossem outros, fazem de conta que são alguém que não são, relacionam-se de formas sustentadas pelos papéis que representam, desenvolvendo enredos temáticos; é especificamente essa modalidade que se considera, na teoria histórico-cultural a mais importante para o desenvolvimento infantil.

Por fim, os jogos de regras são brincadeiras regulamentadas por regras impostas ou combinadas entre os jogadores. Nessas brincadeiras há metas a serem atingidas e o resultado é, habitualmente, tangível: ganhar, perder ou empatar.

É nesse panorama geral que convém entender o valor dado às brincadeiras e contextualizar as seguintes palavras de Vigotski, referentes ao âmbito específico do faz de conta:

Por trás da brincadeira estão as alteraçôes das necessidades e as alteraçóes de caráter mais geral da consciência. A brincadeira é fonte do desenvolvimento e cria a zona de desenvolvimento iminente. A açáo num campo imaginário, numa situação imaginária, a criação de uma intenção voluntária, a formação de um plano de vida, de motivos volitivos - tudo isso surge na brincadeira, colocando-a num nível superior de desenvolvimento [...]. Somente nesse sentido a brincadeira pode ser denominada de atividade principal, ou seja, a que determina o desenvolvimento da criança (VIGOTSKI, 2008, p.35). 
Portanto, as brincadeiras não contribuem da mesma forma e no mesmo grau para o desenvolvimento infantil: é precisamente no faz de conta que se encontra, potencializada, a possibilidade de criação de zonas de desenvolvimento iminente (VIGOTSKI, 2008) e é essa a modalidade definida como atividade principal da infância (LEONTIEV, 1978; 2010).

A natureza social da capacidade de brincar de faz de conta é nuclear nessa teoria. A atividade lúdica não é natural nem onipresente ao longo da história das diferentes sociedades e grupos culturais ${ }^{4}$. $\mathrm{Na}$ ontogênese, essa não naturalidade implica a necessidade de que se ensine as crianças a brincar, sem o que elas não o farão. Nas palavras de Elkonin, a "impressão de espontaneidade no desenvolvimento do jogo de papéis nas crianças surge como consequência de que os adultos não se dão conta da direção que eles, de uma forma natural, realizam" (Elkonin, 2009, p. 178). Ou seja, "[...] a brincadeira na criança não é instintiva, mas precisamente humana” (Leontiev, 2010, p.120).

Das primeiras açóes, como dirigir um pente à cabeça de uma boneca, "penteando-a", até o desenvolvimento de uma brincadeira de saláo de beleza — como a do episódio apresentado — composta por vários papéis, açóes e relaçóes entre eles, é um longo caminho, que demanda vários anos e, sobretudo, recursivas mediaçóes sociais e semióticas. O início da capacidade de brincar marca-se por açóes vinculadas ao contexto: a boneca e um pente são essenciais para a ação de "pentear". Gradualmente, as crianças tornam-se capazes de realizar açóes fictícias com objetos substitutivos - um graveto no lugar do pente, por exemplo —, denominados por Vigotski de objetos-pivô; aprendem a agir em função do que têm em mente e não apenas do que está disponível. No desenvolvimento da capacidade de brincar, portanto, é relevante destacar "a mudança do caráter aliciante do jogo que, nos primeiros anos da infância, surge sob o impacto dos brinquedos, e mais tarde, sob o impacto da ideia, independentemente dos brinquedos" (ELKONIN, 2009, p. 235).

A participação da linguagem na constituição dessa capacidade é crucial, permitindo independência crescente do empírico-sensível, tornando possível realizar ações simbólicas sem objetos-pivô, sustentando-as com a palavra e os gestos. Essa capacidade está em jogo quando Carla "fecha a janela” imaginária do guichê (turno 4); quando Júlia "pas- 
sa esmalte" na unha de Kesya (turno 16); e quando Bia "passa sombra e batom" em si (turno 23).

Embora essa função da linguagem seja especialmente relevante para transformaçóes das possibilidades de brincar, certamente não é a única. Analisando o desenrolar dos episódios podemos ressaltar múltiplos modos de uso da fala que, de diferentes maneiras, dão sustentação às brincadeiras.

No primeiro episódio, contextualizado pela estabilizaçáo da significaçấo da estrutura metálica como "guichê" (usada em dias consecutivos como esse cenário) as interações entre a "vendedora", "compradora/mãe" e "filha" se sustentam, exclusivamente, pelos diálogos dos personagens. Mesmo no único enunciado que não é, propriamente, relacionado ao desempenho de papéis (o pedido de ajuda de Bruna para a professora, expresso no turno 5), estão presentes elementos da situação imaginária, pois ela chama a colega de "moça” e se queixa de sua ação simbólica de fechar a "porta do guichê".

Já no segundo episódio, é por meio da linguagem oral que Júlia assume o controle da brincadeira e, embora implicitamente, dá pistas de estar ocupando o papel de dona do saláo de beleza, ou alguma posição correlata. No comando, Júlia dá ordens dirigindo-se à "freguesa" (turno 17), à "funcionária" (turnos 24, 25 e 26) e a todos (turno 13); narra o que está fazendo/vai fazer; nesse jogo enunciativo, a linguagem vai dando sustentação e veracidade a algumas ações e objetos fictícios (turno 10, por exemplo). Os parceiros de Júlia acatam suas proposiçóes e legitimam sua palavra de que objetos muito similares podem ser pivôs ou náo, podem substituir ou não o creme de cabelo (turno 25). Também por meio de suas falas e gestos, os parceiros constroem, conjuntamente, a brincadeira de salâo de beleza, respeitando o caráter complementar dos papéis assumidos. Sendo assim, "Mesmo sendo uma reprodução do vivenciado e conhecido, o jogo imaginário constrói-se com base na diversidade e na criatividade [sobretudo] nos modos pelas quais as falas das crianças vão constituindo a sequência do faz de conta e seus personagens" (GÓES, 2000, p. 12).

Demarcado o conceito de atividade lúdica e explicitado o papel e a importância da linguagem nas brincadeiras de faz de conta, segundo 
o referencial teórico aqui assumido, examinaremos episódios registrados em turma de primeiro ano do EF. Com o trabalho analítico poderemos consubstanciar o que apontam as pesquisas quanto às brincadeiras nesse segmento. Entretanto, nosso intuito não é meramente confirmar que, apesar da precariedade das condiçôes, as crianças brincam no dia a dia escolar. Também evidenciaremos que essa atividade realiza-se de modos distintos na sala de aula, no recreio e na educação física, sendo afetada pelo contexto e por recursos disponíveis.

\section{"AQUI NÃO É LUGAR DE BRINCAR": O COTIDIANO DE UMA TURMA DE PRIMEIRO ANO}

A pesquisa de campo foi realizada em uma escola municipal, localizada em Campinas, cidade do interior do Estado de Sáo Paulo (Brasil). Essa escola atende, predominantemente, a crianças de classes populares, residentes em bairros da periferia. Do conjunto de informaçóes, recortamos as produzidas por observaçóes do cotidiano escolar ${ }^{5}$, numa frequência de uma vez por semana, ao longo do segundo semestre letivo.

As palavras que abrem esse tópico foram ditas por uma aluna a dois colegas que engatinhavam pela sala. A frase completa é: "Aqui não é lugar de brincar. Brincar é só na hora do recreio e na sala é para fazer lição". Essa frase tem dupla importância para compreendermos o cotidiano da turma. Primeiro, porque é uma síntese do que a professora procura nele imprimir, reproduzida e assumida pela aluna. Em segundo lugar, pela contradição quando se compara a prescrição com o que de fato ocorre na "sala de fazer lição".

A classe é de tamanho médio, comportando bem as carteiras dos 24 alunos. A rotina da turma da professora Zélia é regular: no primeiro período, das 7 às 9 horas, as crianças devem ficar sentadas em suas carteiras, desenvolvendo atividades de escrita, prioritariamente, feitas numa apostila, num caderno pautado e num de caligrafia. Após isso, há intervalo de 20 minutos, destinados à merenda e ao recreio; por 10 minutos, os alunos podem brincar num corredor cimentado, com pilastras em toda área, que dificultam a movimentação. Depois do intervalo voltam para a sala, fazem mais uma atividade; nas terças e quintas-feiras, vão para 
a aula de educação física, na quadra. Quando a professora falta, as crianças permanecem na sala, fazendo atividade. A organização do mobiliário é feita do modo escolar tradicional: carteiras enfileiradas e mesa da professora colocada à frente ${ }^{6}$. Durante a observaçáo, a professora agrupou duas vezes as carteiras; nessas ocasióes usou dois jogos (Cilada e Top Letras).

$\mathrm{O}$ uso de material lúdico na sala de aula foi restrito a jogos de regras, embora tanto Cilada quanto Top Letras não tenham sido realmente jogados, pois a professora adaptou as regras. No Top Letras orientou as crianças a escreverem seus nomes e uma palavra que conheciam, encaixando as letras na base. Alguns tentaram escrever, outros se desinteressaram, empilharam as peças, compararam as letras... Um jogo de Palavras Cruzadas também foi usado pela professora, duas vezes; as crianças tiveram, novamente, dificuldades para jogá-lo.

No período do recreio, observamos as crianças em pega-pega (a brincadeira mais frequente), pega-alto, polícia e ladrão, brincadeiras com as mãos (do tipo Adoleta e tapinha), escorregar no corrimão, subir e descer em uma mureta, lutinha. Em alguns dias, pularam corda.

$\mathrm{Na}$ educação física, registramos as seguintes atividades: chute ao gol, pular corda, percorrer circuitos, salto em altura, futebol. Embora a professora pedisse que ficassem sentados em uma linha pintada no chão ou em fila, aguardando a vez, vários episódios de brincadeiras em pequenos grupos ou individualmente ocorreram. Ou seja, contrapondo-se às ordens da professora, os alunos aproveitavam as brechas na vigilância e brincavam. Não obstante a frequência de brincadeiras fosse grande, há três aspectos a serem notados:

1. curta duração (de poucos segundos a três minutos);

2. sua repetição num mesmo dia e ao longo dos meses; e

3. a forte predominância de jogos de exercício.

Paradas de mão, estrelas, subir e descer de uma mureta e as mesmas brincadeiras com as mãos observadas no recreio (do tipo Adoleta) foram recorrentes. Algumas vezes, a professora chamou a atenção das 
crianças, para que parassem de brincar, ficassem em ordem e quietos; em outras, permitiu que se movimentassem, sem repreendê-los.

Considerando-se as atividades observadas no recreio e na educação física, poderíamos concluir que as brincadeiras de faz de conta são praticamente inexistentes no dia a dia da turma, sendo predominantes jogos de exercício e de regras.

Entretanto, na sala de aula, a cada dia foi possível observar episódios de pequeníssima duração (de poucos segundos a um minuto e meio) em que outras brincadeiras ocorreram. Os próximos trechos ilustram essas ocorrências.

Excerto 1: John, Maria e Evelin pegaram as folhas com o desenho de um coelhinho para pintar e fazem de conta que os animais estão saltando.

Excerto 2: Wesley chuta o seu estojo que caiu no chão, passando-o entre as pernas da carteira do colega e diz "gooolll".

Excerto 3: Karlen cutuca o amigo Carlos e sai trotando, fazendo sons de relincho.

Excerto 4: Carlos volta da mesa da professora andando como um robô.

Excerto 5: Evelin pega seu laço de cabelo "varre" a sua mesa. Thalyta pega um lápis, coloca perto da boca, olha para um colega, dá uma reboladinha como se fosse uma cantora.

Excerto 6: Everton apoia o pé na parte alta de sua mesa e faz de conta que dirige um carro; faz sons do motor, aumentando e diminuindo a "velocidade"; usa o lápis como câmbio.

Excerto 7: Jenny joga a borracha na mesa do colega; o colega olha para ela. Jennifer pega a tesoura e passa várias vezes em volta da mesa fazendo barulho de carro de corrida; o colega faz a mesma coisa, porém com o lápis.

Excerto 8: Jenny e Wesley, com seus lápis, simulam luta com espadas.

Excerto 9: Silvan alinha alguns lápis como uma pista e brinca de corrida fazendo um dedo deslizar na pista, imitando, baixinho, o som de carros de corrida. 
Excerto 10: Elvis finge dirigir, andando e correndo pela sala, freando e fazendo curvas.

Excerto 11: Lauren anda de quatro entre as carteiras; José faz de conta que dá comida para Lauren; depois faz gestos típicos de chamar cachorros, estalando os dedos. Lauren finge comer.

Excerto 12: Lucas faz um aviãozinho de papel; joga no corredor entre as carteiras e engatinha para resgatá-lo. Pedro, animado e interessado na brincadeira, diz para Lucas: "vai rápido antes que a professora veja”.

Esses trechos não esgotam os registros de brincadeiras ocorridas em sala. Sáo, porém, suficientes para ilustrar que se a professora usa os jogos como material didático (como fez com Cilada, Top Letras e Palavras Cruzadas), as crianças fazem o movimento inverso e transformam suas borrachas, seus estojos, seus lápis em objetos lúdicos. Por vezes, buscam cúmplices, com estratégias sagazes — um lápis derrubado no chão, olhar convidativo - , encontram formas de burlar o lema geral de que a sala de aula não é lugar para brincar. Em outras pesquisas, microepisódios de faz de conta bem semelhantes também foram registrados (OLIVEIRA, 2013; AZEVEDO, 2012; MARCONDES, 2012; MARTINATI, 2012; CAMPOS, 2011; NOGUEIRA, 2011; NEVES, 2010), assim como as mesmas reaçóes das professoras diante dessas brincadeiras: sempre que flagradas, as crianças são censuradas, advertidas e algumas vezes punidas.

Constatar o uso sistemático dessas estratégias é importante, mas não deve ser considerado como suficiente para suprir a escassez de brincadeiras de faz de conta. Primeiro, porque nem todas as crianças conseguem fazer essas transgressóes e parte delas passa os dias escolares obedecendo às ordens de não brincar. Em segundo lugar, porque são muito simples e não representam as formas mais sofisticadas pelas quais poderiam ser desenvolvidas, como ilustramos nos episódios do guichê e do salão de beleza. Destacamos que, do ponto de vista do importante papel da linguagem, poucos enunciados são produzidos; quando ocorrem, são muito simples, sendo mais frequentemente onomatopeias, representando barulhos de carros, de animais. Não registramos, e não encontramos em nenhuma das teses e dissertaçóes, brincadeiras que se 
estruturassem em torno de alguma temática, na qual as crianças desenvolvessem enredos e desempenhassem papéis articulados entre si, que indiciassem elaboraçóes sobre as relaçóes sociais e a cultura via operaçóes, mais complexas, no campo simbólico e da imaginação.

Assim, brincando de faz de conta em situaçôes nas quais estão proibidas de fazê-lo, as crianças realizam açôes lúdicas bastante elementares. É certo que não sabemos exatamente o que ocorre no plano interno, se, em silêncio, pronunciam enunciados, relacionam-se com alguém imaginado, assumem papéis. Mas, mesmo que assim o seja, nas circunstâncias em que ocorrem e na duraçáo que têm, só podem ser formulaçóes muito simples.

Outra particularidade dos microepisódios de faz de conta é que eles se iniciavam de modo fortuito e náo como resultado de planejamento ou de combinaçóes, como costumava ocorrer com a turma de EI. É restrito, portanto, também nesse âmbito, o papel da linguagem, mostrando-se pouco usual uma dinâmica em que

[...] mais ricas se tornam as possibilidades de organização da ação partilhada na brincadeira. Dizer uma à outra como usar determinado objeto ou brinquedo, combinar o tema, distribuir os papéis e organizar o cenário da brincadeira são algumas das coordenaçóes que só se tornam possíveis com o desenvolvimento da linguagem (CRUZ, 2015, p. 79).

É importante destacar, por fim, as diferenças de modalidades de brincadeiras registradas, a depender do contexto focalizado: de modo predominante e consistente, as crianças envolveram-se em jogos de exercício e regras no recreio e nas brechas da educação física e em jogos de faz de conta nas brechas da aula, na sala. A mesma tendência pode ser identificada nas teses e dissertaçóes analisadas. Perguntamos, então: o que há nessas circunstâncias que nos ajuda a compreender a regularidade de distintos modos de brincar? De múltiplos aspectos que podem ser elencados, conjecturamos que a possibilidade de sustentar ações lúdicas com objetos faz diferença. Essa questão nos permite retomar o que foi 
apontado como progressiva independência das condiçóes concretas em que o faz de conta pode acontecer e argumentar que a disponibilidade de objetos e de objetos-pivôs segue sendo necessária, mesmo quando se trata de crianças, em geral, já bastante experientes. A ausência de objetos — tal como ocorre no recreio e na educação física — implica a quase ausência dessa modalidade de brincadeiras nesses contextos. Quase o mesmo pode ser dito em relação aos jogos de regras; porém, como vimos, algumas brincadeiras desse tipo são realizadas sem nenhum suporte material, como é o caso do pega-pega, bastante frequente na turma.

Sendo assim, às conclusôes gerais das pesquisas sobre as condições adversas para a atividade lúdica no EF, acrescentamos outro problema: essa adversidade impacta mais justamente o que temos considerado como a mais importante forma de brincar das crianças na nossa cultura. De nossa perspectiva, essa é uma questão que requer atenção ainda não suficientemente dispendida.

\section{CONSIDERAÇÕES FINAIS}

Ao longo deste artigo, fomos evidenciando a grande distância entre o que se projetou para o EF de nove anos e o que vem se materializando, em contextos concretos de turmas de primeiros anos, destacando questôes relativas à atividade lúdica. Nosso foco recaiu, principalmente, sobre o trabalho de professoras, os limites de suas açóes para oferecer maiores e melhores possibilidades para as crianças brincarem e desenvolverem-se nessa esfera de atividade humana. É necessário, entretanto, ao finalizar o texto, ressaltar que essa questão está longe de ser de responsabilidade única de docentes e que muitos deles viveram e vivem com muito desconforto as restriçóes que acabam impondo a seus alunos. A inclusão de brincadeiras no cotidiano escolar não é nada simples, requer açóes que ultrapassam decisóes individuais e o enfrentamento de desafios variados: adequar a estrutura física, construir e disponibilizar acervo de brinquedos e jogos, convencer os pais de que o tempo das brincadeiras não é um tempo perdido, dentre outros. Então, se de fato 
nosso projeto para a infância inclui a construção de um currículo renovado, é necessário que nos empenhemos em debates e em açóes coletivas para a sua consecução.

\section{REFERÊNCIAS}

AZEVEDO, N.C.S. Programa "Cidadescola" no $1^{\circ}$ Ano do Ensino Fundamental em uma Escola de Presidente Prudente: entre a ludicidade e a sala de aula. Universidade Estadual Paulista "Júlio De Mesquita Filho". Programa de Pós-Graduação em Educação Dissertação. Presidente Prudente, 2012.

BRASIL. Ministério da Educação e Cultura. Secretaria de Educação Básica. Ensino Fundamental de Nove Anos - Orientações Gerais. Brasília: MEC/SEB. 2004.

. Ministério da Educação. Secretaria de Educação Básica, Departamento de Políticas de Educação Infantil e Ensino Fundamental, Coordenação-Geral do Ensino Fundamental. Ensino Fundamental de Nove Anos: orientaçóes para a inclusão da criança de seis anos de idade. +1 ano é fundamental. Brasília: SEB/ DPE/COEF, 2006.

. Ministério da Educação. Secretaria de Educação Básica, Diretoria de Concepçôes e Orientaçôes Curriculares para Educação Básica, Coordenação-Geral do Ensino Fundamental. Ensino fundamental de nove anos: passo a passo do processo de implantaçáo. 2a ed. Brasília: Ministério da Educação, set. 2009. Disponível em: <http://portal.mec.gov.br/dmdocuments/passo a passo versao atual_16_setembro.pdf>. Acesso em: 21 de julho de 2017.

CAMPOS, J.O. A criança de 6 anos no ensino fundamental de 9 anos na perspectiva da qualidade na educação infantil. Universidade de Brasília. Programa de Pós-graduação em Educação. Dissertação. Brasília. 2011.

CHULEK, V. A educação infantil e o ensino fundamental de nove anos nas vozes de crianças e na organização do trabalho pedagógico de duas instituiçōes de Curitiba-PR. Universidade Federal do Paraná. Dissertação. Curitiba. 2012.

CRUZ, M.N. O brincar na educação infantil e o desenvolvimento cultural da criança. In: SILVA, D.N.H.; ABREU, F.S. (orgs.). Vamos brincar de quê?? Cuidado e educação no desenvolvimento infantil. São Paulo: Summus. 2015.

ELKONIN, D.B. Psicologia do jogo. São Paulo: Martins Fontes. 2009.

GÓES, M.C.R. Ojogo imaginário na infância: a linguagem e a criação de personagens. In: 23a Reunião Anual da ANPED, 2000, Caxambu, MG. Anais..., 2000. 
LEONTIEV, A.N. O desenvolvimento do psiquismo. Lisboa: Horizonte, 1978.

. Os princípios psicológicos da brincadeira pré-escolar. In: VYGOTSKY, L.S.; LURIA, A.R.; LEONTIEV, A.N. Linguagem, desenvolvimento $e$ aprendizagem. São Paulo: Ícone, 2010.

MARCONDES, K.H.B. Continuidades e descontinuidades na transição da educação infantil para o ensino fundamental no contexto de nove anos. 2012. $374 \mathrm{f}$. Tese (Doutorado) - Universidade Estadual Paulista, Faculdade de Ciências e Letras de Araraquara, 2012. Disponível em: <http://hdl.handle.net/11449/101554>. Acesso em: 07 de agosto de 2017.

MARTINATI, A.Z. Faz de conta que eu cresci: o processo de transição da Educação Infantil para o Ensino Fundamental. 2012. 233 f. Dissertaçáo (Mestrado em Educação) - Pontifícia Universidade Católica de Campinas, Campinas, SP, 2012. Disponível em: $<$ http://tede.bibliotecadigital.puc-campinas.edu.br:8080/ jspui/handle/tede/706>. Acesso em: 07 de agosto de 2017.

NEVES, V.F.A. Tensöes contemporâneas no processo de passagem da educação infantil para o ensino fundamental: um estudo de caso. 2010. $270 \mathrm{f}$. Tese (Doutorado em Educação) - Programa de Pós-graduação em Educação. Faculdade de Educação. Universidade Federal de Minas Gerais, Belo Horizonte, MG, 2010.

NOGUEIRA, G.M. A passagem da educação infantil para o $1^{\circ}$ ano no contexto do ensino fundamental de nove anos: um estudo sobre alfabetização, letramento e cultura lúdica. 2011. 297 f. Tese (Doutorado em Educação) - Universidade Federal de Pelotas, Pelotas, RS, 2011. Disponível em: <http://hdl.handle. net/123456789/1614>. Acesso em: 07 de agosto de 2017.

OLIVEIRA, D.R. A formação continuada de professores de primeiro ano do ensino fundamental de nove anos e os desafios ao trabalho pedagógico. 2011. $167 \mathrm{f}$. Dissertação (mestrado) - Universidade Estadual Paulista, Faculdade de Ciências e Tecnologia, Presidente Prudente, SP, 2011. Disponível em: <http://hdl.handle.net/11449/92318>. Acesso em: 07 de agosto de 2017.

OLIVEIRA, L.D. Bem-vinda à Escola: o ingresso da criança no primeiro ano do ensino fundamental sob o olhar docente e a perspectiva do brincar. 2013. 137 p. Dissertação (mestrado) - Universidade Estadual de Campinas, Faculdade de Educação Física, Campinas, SP, 2013. Disponível em: < http://repositorio. unicamp.br/bitstream/REPOSIP/275121/1/Oliveira LucianaDiasde M.pdf>. Acesso em: 07 de agosto de 2017.

ROCHA, M.S.P.M.L. A atividade lúdica, a criança de 6 anos e o ensino fundamental. Revista Semestral da Associação Brasileira de Psicologia Escolar e Educacional (ABRAPEE), v. 13, n. 2, p. 203-212, jul./dez. 2009. 
SANTOS, M.S.P. A Atividade lúdica nas práticas pedagógicas dos ingressantes no ensino fundamental: análises das aulas de Educaçâo Física. 2013. 98 f. Dissertação (Mestrado em Educação) - Pontifícia Universidade Católica de Campinas, Campinas, SP, 2013. Disponível em: $<$ http://tede.bibliotecadigital. puc-campinas.edu.br:8080/jspui/handle/tede/717>. Acesso em: 07 de agosto de 2017.

SILVA, I.Z. O espaço do brincar em uma escola municipal. 2011. 163 f. Dissertação (Mestrado) - Universidade Estadual de Campinas, Faculdade de Educação, Campinas, SP, 2011. Disponível em: <http://repositorio.unicamp.br/handle/

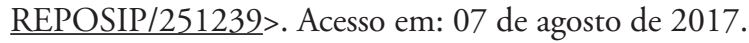

VIGOTSKI, L.S. A brincadeira e o seu papel no desenvolvimento psíquico da criança. Revista Virtual de Gestáo de Iniciativas Sociais. Rio de Janeiro, n. 11. p. 23-36, jun. 2008.

\section{NOTAS}

1. É importante ressaltar que o conceito de atividade principal (em alguns textos também designada como atividade-guia), não é sinônimo da principal atividade (em termos de mais frequente) de que se ocupam as crianças no período pré-escolar. Essa distinção pode ser encontrada em trabalhos de L. S. Vigotski (2008), A. N. Leontiev (1978; 2010) e D. B. Elkonin (2009). A título de síntese, atividade principal é aquela em que, por suas características estruturais e funcionais, constituem as mais importantes transformações das funçóes psicológicas e de suas inter-relações, na composição do sistema psíquico humano. No período pré-escolar, a brincadeira de faz de conta é apontada como o mais importante meio de relação entre as crianças e o mundo social, tendo em vista as peculiares possibilidades que oferece de interpretação e de elaboraçóes sobre as diversas esferas da vida humana e de si próprias, envolvendo complexas relaçóes entre a imaginação, a memória, a percepção, a linguagem, a cognição e os afetos.

2. Todos os nomes das crianças são fictícios.

3. As definiçôes apresentadas sobre essas três modalidades de brincadeiras foram elaboradas pela primeira autora deste artigo, buscando sintetizar suas principais características. Considerando a fundamentação na perspectiva histórico-cultural, uma ressalva é necessária: nos trabalhos de alguns autores dessa teoria encontramos outras nomenclaturas - por exemplo, a denominação de jogo protagonizado, utilizada por Elkonin (2009), referindo-se ao que aqui chamamos de faz de conta, bem como outras modalidades — , por exemplo os jogos denominados por Leontiev (2010) de jogos limítrofes (subdivididos pelo autor em jogos didáticos, jogos de dramatizaçáo e jogos de fantasia). 
4. Na obra Psicologia do Jogo, de D. B. Elkonin (2009), há diversos estudos antropológicos que dão farto apoio empírico à tese de que o faz de conta não é universal.

5. O trabalho de campo incluiu observação do cotidiano e de reunióes de pais e mestres, entrevistas com a professora e pais/responsáveis.

6. Como em muitas turmas de primeiros anos, o mobiliário não foi adaptado e as carteiras são grandes demais; para minimizar o desconforto, os alunos ficam em pé ou ajoelham-se na cadeira, sendo, frequentemente, censurados pela professora.

Recebido em 14 de janeiro de 2017.

Aprovado em 24 de junho de 2017. 